\title{
Severe plastic deformation of AA 5083 and copper bimetallic metal
}

\author{
Ananda Babu Varadala ${ }^{1}$ (D) Swami Naidu Gurugubelli ${ }^{2} \cdot$ Sateesh Bandaru ${ }^{3}$
}

Received: 9 May 2020 / Accepted: 20 August 2020 / Published online: 26 August 2020

(c) Springer Nature Switzerland AG 2020

\begin{abstract}
The purpose of the present study is to investigate the effect of Cu casing and wall thickness of the drilled copper bars on uniform distribution of imposed stain in terms of structural homogeneity and distribution of micro-hardness in the severely deformed AA 5083 after equal channel angular extrusion (ECAE). In this study, AA 5083 cylindrical inserts of $6 \mathrm{~mm}, 8 \mathrm{~mm}$ and $10 \mathrm{~mm}$ diameter with $100 \mathrm{~mm}$ length are tightly inserted in the $16 \mathrm{~mm}$ square copper bars having the respective diameter holes. The square cross sectioned AA 5083 billets of $16 \mathrm{~mm} \times 16 \mathrm{~mm}$ and $100 \mathrm{~mm}$ length are also considered as feedstock. The longitudinal surfaces of the bimetallic metals are polished and annealed at $530^{\circ} \mathrm{C}$ for $1 \mathrm{~h}$ and then processed by ECAE up to four passes in route A (same sense after every pass without any rotation) at room temperature using a die with square cross-sectioned channels having channel intersection angle $(\phi) 105^{\circ}$ and outer corner angle $(\Psi) 30^{\circ}$. The initial grain size of $60 \mu \mathrm{m}$ has been greatly refined and the ultrafine grains of the sizes in the range of 400-700 nm are formed in the extruded AA 5083 inserts after the four passes. The microhardness of extruded AA 5083 significantly increased from 69 to $134 \mathrm{VHN}, 132,176$ and 157 respectively for the square billets without Cu casing and cylindrical inserts with the diameters of 6,8 and $10 \mathrm{~mm}$ covered with Cu casing after the four passes. The variations in the microhardness measurements at different regions on the sectioned surfaces are also investigated in this study. The requirement of pressing force is very significantly reduced by using copper casing which is having more ductile nature and the frictional forces between the copper and steel die are very less as compared to the Aluminium and steel. The chances of formation of dead metal zone are avoided by filling the corner gap by cooper metal during the ECAE process. The uniform distribution of strain imposed on the severely deformed billets develops the homogeneous ultrafine grain structure and significantly improves the micro-hardness of the processed material.
\end{abstract}

Keywords ECAE $\cdot \mathrm{Al}-\mathrm{Mg}$ alloy $\cdot$ Grain refinement $\cdot$ Copper casing $\cdot$ Microhardness

\section{Introduction}

Equal channel angular extrusion is a most significant process among various Severe Plastic Deformation (SPD) processes for improving mechanical properties of materials by producing ultrafine grains [1]-[3].The process of ECAE uses a die having two channels of similar crosssection connected at a specified channel angle $(\phi)$ and outer angle $(\Psi)$ [4]. When the material passes through the plastic deformation portion of the die high shear strain is induced in the materials $[5,6]$. The processing route can be altered between the successive passes by using different orientations of the billets in $0^{\circ}$ (route-A), $90^{\circ}$ in an alternate orientation (route- $B_{A}$ ), $90^{\circ}$ in same orientation (route- $B_{C}$ ) and $180^{\circ}$ (route-C) [7]. Selection of appropriate die angles, pressing route $\left(A, B_{A}, B_{C}, C\right)$, pressing speed, pressing temperature and number of passes control the strain developed and the microstructural changes $[8,9]$. ECAE with casing is a novel technique in which the billet is inserted in the metallic or non-metallic casing or capsule

\footnotetext{
$\triangle$ Ananda Babu Varadala, varadalaanand@gmail.com | 'Department of Mechanical Engg., Vignan's Insti. of Engg. for Women, Visakhapatnam 530046, India. ${ }^{2}$ Department of Metallurgical Engg., JNTUK-UCEV, Vizianagaram 535003, India. ${ }^{3}$ Department of Mechanical Engg., Vignan's Inst. of Info. Techn., Visakhapatnam 530046, India.
} 
[10]- [12]. Copper is used as a casing in ECAE by considering its good frictional properties. Research findings have shown the benefits of a casing for the billet to achieve more deformation homogeneity and cracking free billets.

Djavanroodi et al. applied a novel technique called Covered Tube Casing (CTC) in order to improve the strain distribution and deformation homogeneity in the extruded sample [13]. The strain distribution in normal and longitudinal directions of the billet using experimentation and simulation methods is studied. It is shown that the homogeneity in strain distribution can be improved by making use of the copper shielding in ECAE process than the conventional ECAE. Shaeri al. observed the significance of copper shielding on the distribution of induced strain and behaviour of ECAPed Al 7050 alloy through simulation and experimentation and observed that the structural homogeneity, hardness, and strength increased with increasing the casing thickness [14]. Djavanroodi et al. performed ECAE of copper tubes in various routes of $A, B_{A}, B_{C}$ and $C$ up to three pressings in the channels bent by $90^{\circ}$ and assessed the effect of routes on the hardness homogeneity [15].

In this study, the structural analysis and micro-hardness variations in the ECAEd AA 5083 circular and square billets of with and without $\mathrm{Cu}$ casing are performed. The square billets without $\mathrm{Cu}$ casing and cylindrical billet with $\mathrm{Cu}$ casing are subjected to ECAE up to four passes using a die having channel intersection angle $105^{\circ}$ and corner angle $30^{\circ}$ up to four passes in route $A$.

\section{Materials and methods}

Commercial Al-4.5Mg alloy (AA 5083) of O-grade is considered as feedstock in this study. The square billets of $16 \mathrm{~mm} \times 16 \mathrm{~mm} \times 100 \mathrm{~mm}$ length and circular billets with $90 \mathrm{~mm}$ long and 6, 8, $10 \mathrm{~mm}$ diameters and $100 \mathrm{~mm}$ length are machined from rolled plate. The copper bars of $100 \mathrm{~mm}$ length and $16 \mathrm{~mm}$ square cross section are drilled longitudinally with the diameters of $6 \mathrm{~mm}, 8 \mathrm{~mm}$ and $10 \mathrm{~mm}$. The bi-metallic materials with press fit are obtained by inserting the circular billets of $6 \mathrm{~mm}, 8 \mathrm{~mm}$ and $10 \mathrm{~mm}$ diameters in the drilled portions of the copper bars with $6 \mathrm{~mm}, 8 \mathrm{~mm}$ and $10 \mathrm{~mm}$ diameters respectively. The schematic representation of $\mathrm{Cu}$ drilled bars and AA 5083 cylindrical inserts are shown in Fig. 1. The bi-metallic materials and square billets without $\mathrm{Cu}$ casing are annealed at $530^{\circ} \mathrm{C}$ for $1 \mathrm{~h}$ and then ECAEd as depicted in Fig. 2 using a die having the channel intersection angle $(\phi) 105^{\circ}$ and outer corner angle $(\Psi) 30^{\circ}$. The effective strain induced in the extruded material using the die with the above angles is 0.863 per cycle. Molybdenum disulphide $\left(\mathrm{MoS}_{2}\right)$ lubricant is applied to the billets and the die channels prior to performing ECAE. The bi-metallic materials are heated to warm conditions between successive cycles to remove stresses produced during ECAE and for homogenization of the structure. Figure 3 shows the ECAEd AA 5083 billets without $\mathrm{Cu}$ casing and bi-metallic materials with $\mathrm{Cu}$ casing after the four cycles in route $A$ with the notations of three directional planes i.e., normal plane (NP),longitudinal plane (LP) and transverse plane (TP) are represented.

The ECAEd samples are then sectioned along the normal plane (NP) i.e., perpendicular to the longitudinal axis to perform the structural analysis. The extruded $\mathrm{Al}-\mathrm{Mg}$ alloy samples were then prepared according to the standard sample preparation procedures and the Kellers etching agent is applied to the polished surfaces. The Field Emission Scanning Electron Microscope (FE-SEM) Carl Zeiss MAKE-Neon 40 crossbeam with $1.1 \mathrm{~nm}$ resolution is used to perform the microstructural analysis of ECAEd AA 5083 inserts. The Vicker's microhardness tests were performed at a load of $200 \mathrm{~g}$ for a $20 \mathrm{~s}$ dwell period. The sectioned surfaces of the extruded materials are divided into different circular regions and the microhardness measurements were noted to observe the uniformity in strain distribution in the ECAEd inserts. The average value of the three tests is considered for the evaluation of the behaviour of the extruded material.
Fig. 1 Schematic representation of Cu drilled bars and cylindrical AA 5083 inserts

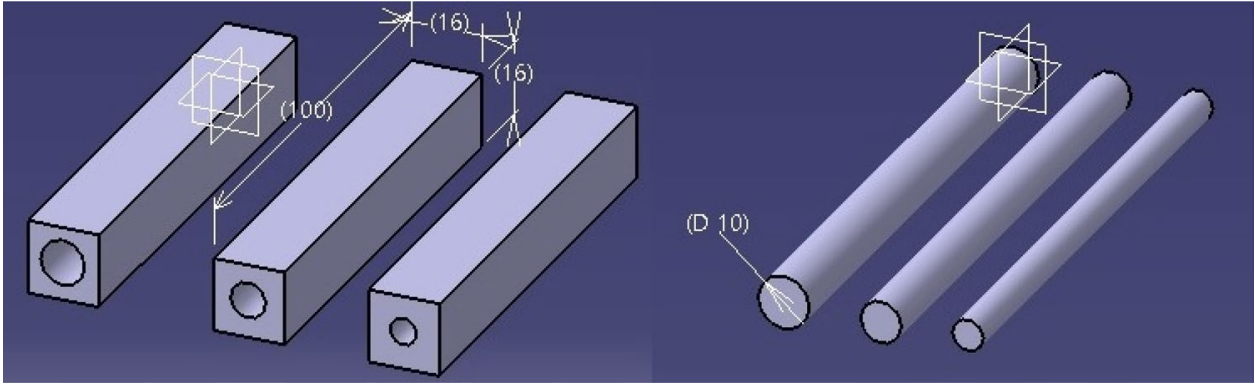



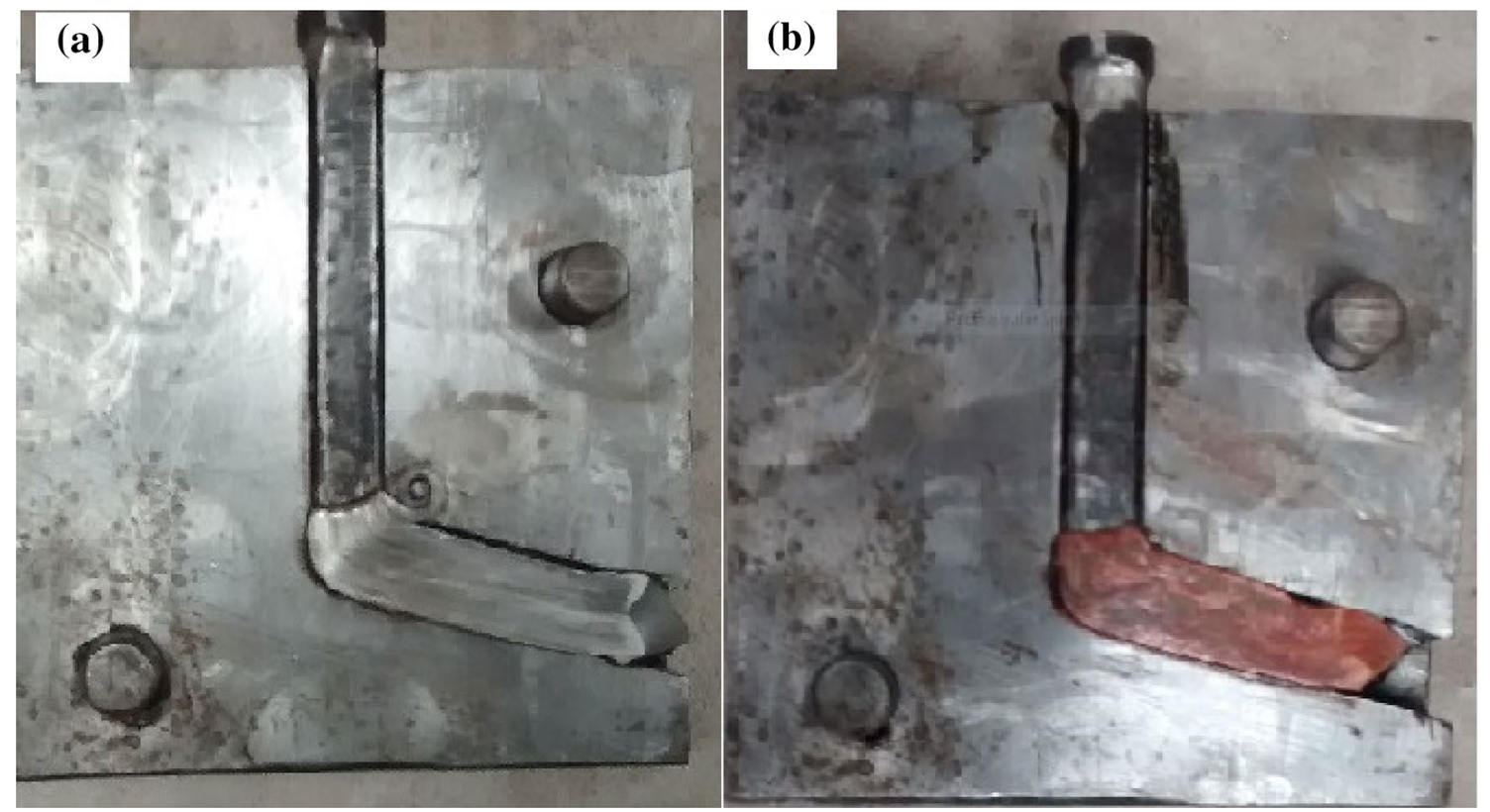

Fig. 2 ECAE of AA 5083 a without Cu casing, b inserts in square copper bar

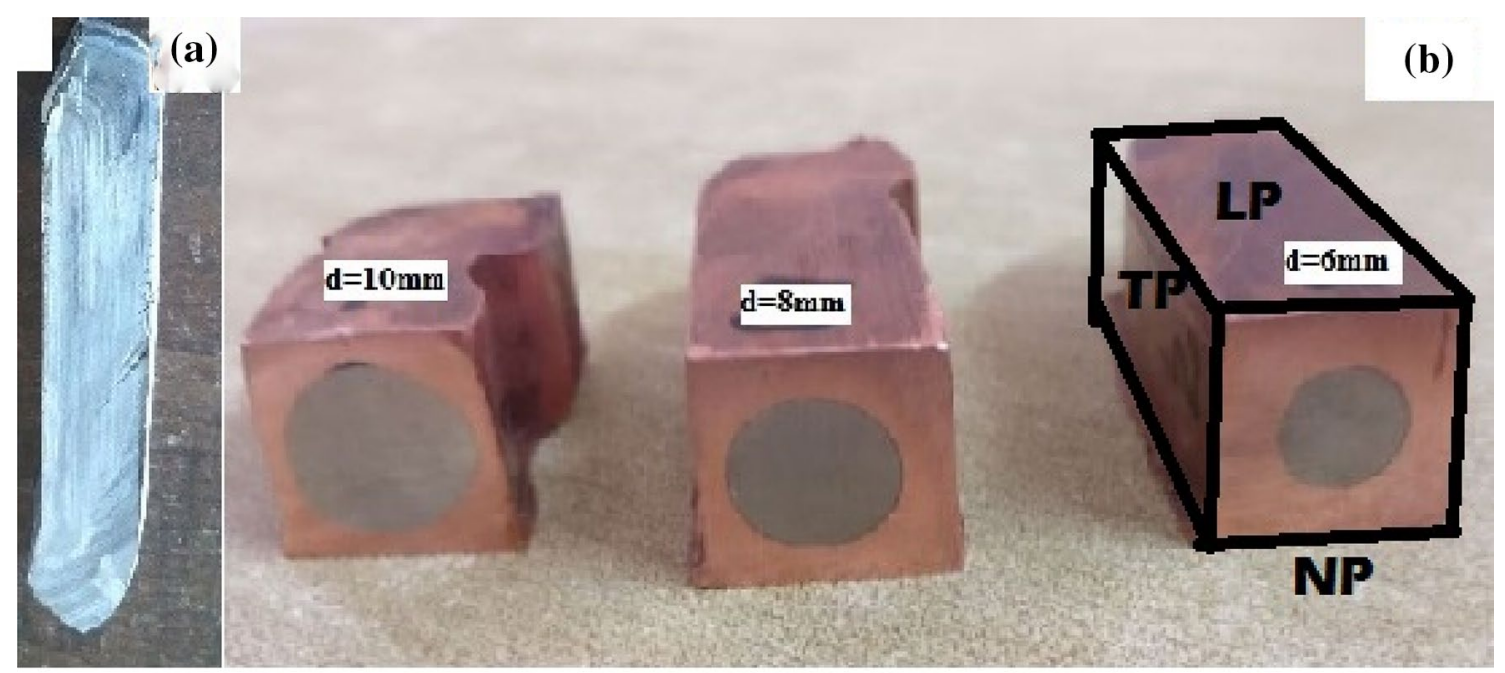

Fig. 3 ECAEd AA 5083 a without Cu Casing and b bi-metallic materials with directional representation

\section{Results and discussion}

\subsection{Requirements of the extrusion load}

The extrusion loads required for ECAE of AA 5083 square billets without $\mathrm{Cu}$ casing and cylindrical inserts in a drilled square copper bars are shown in Fig. 4. The extrusion load required for deformation of bi-metallic materials is less due to the low coefficient of friction between steel die and copper casing [16]. The ductility nature of copper increases the lubrication effect during ECAE of bi-metallic materials and reduces the required extrusion load. It is noticed that during ECAE of bi-metallic materials, the rate of extrusion load increases with increasing the diameter of AA 5083 inserts. It is also observed that the required extrusion load decreases with increasing the number of extrusion cycles for the inserts with $6 \mathrm{~mm}$ and $8 \mathrm{~mm}$ diameters up to second pass due to more casing thickness of $\mathrm{Cu}$ bars but increases after the second pass due to strain hardening. For $10 \mathrm{~mm}$ diameter inserts the required extrusion load increases after every 
Fig. 4 Extrusion Force required for ECAE of without Cu casing and bimetallic materials

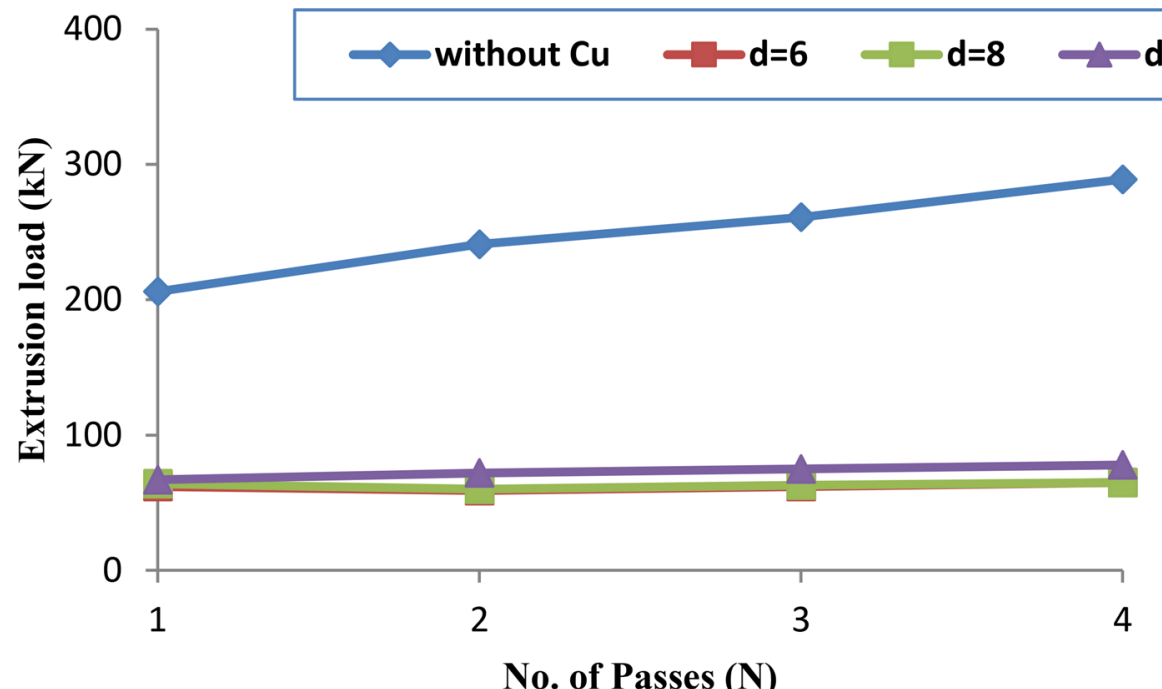

No. of Passes (N)

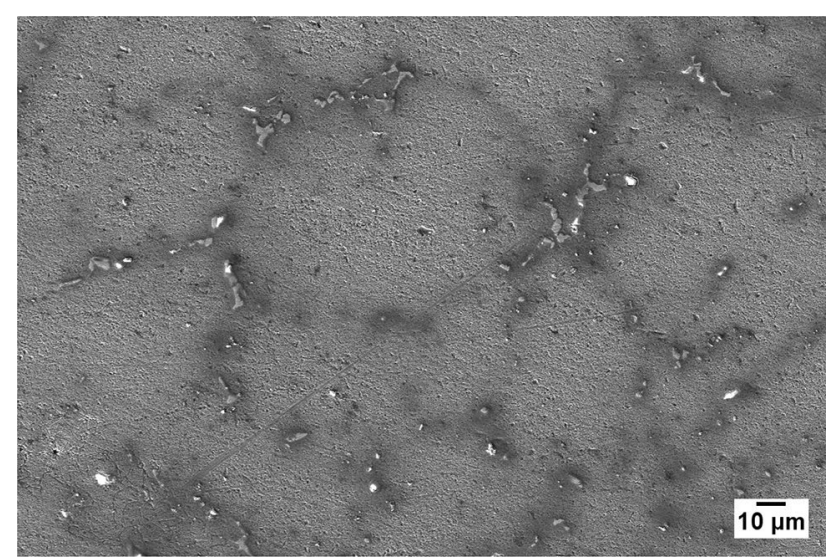

Fig. 5 SEM photograph of AA 5083 before ECAE

pass due to less thickness of $\mathrm{Cu}$ in bimetallic material and strain hardening of materials during the extrusion process.

\subsection{Microstructure}

The SEM photograph of AA 5083 before ECAE is shown in Fig. 5. It is observed that the structure of the AA 5083 material before ECAE having the nonhomogeneous structure with full of coarse grains. The average grain size of the work material before ECAE is $60 \mu \mathrm{m}$.

The significant reduction in grain size is observed in the severely deformed AA 5083 square billetrs processed without $\mathrm{Cu}$ casing and cylindrical inserts with $\mathrm{Cu}$ casing. The SEM images of the square billets without $\mathrm{Cu}$ casing after the first and the fourth pass are shown in Fig. 6. It is observed that the severely deformed alloy without casing having some micro-cracks due to the formation of dead metal zone and excessive strain hardening, even the grain size refines significantly up to few hundreds of nanometers.

The FE-SEM photographs of the ECAEd AA 5083 inserts with $6 \mathrm{~mm}, 8 \mathrm{~mm}$ and $10 \mathrm{~mm}$ diameters in square copper

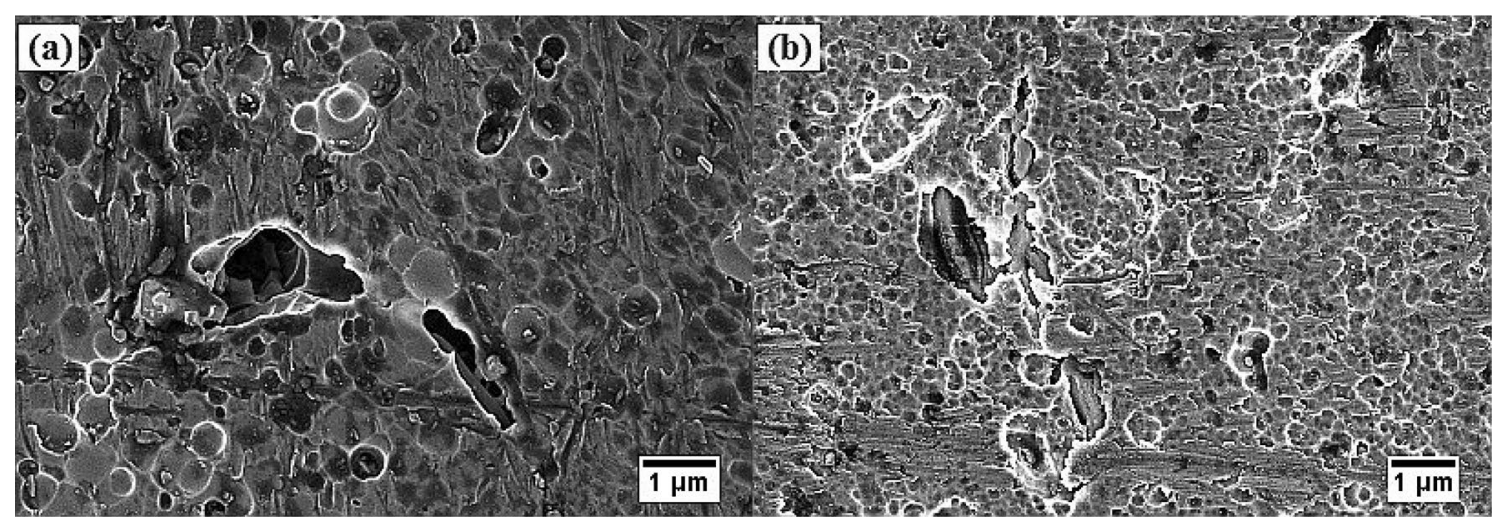

Fig. 6 SEM photographs of ECAEd square AA 5083 billets without Cu casing after. a First pass, $\mathbf{b}$ fourth pass 
drilled bars after the first pass are depicted in Fig. 7. The average grain sizes are about $900 \mathrm{~nm}, 700 \mathrm{~nm}$ and $800 \mathrm{~nm}$ for extruded AA 5083 inserts of $6 \mathrm{~mm}, 8 \mathrm{~mm}$ and $10 \mathrm{~mm}$ diameters respectively after the first pass. The rate of reduction in grain size is very much close to 100 times after the first pass of ECAE in all the processed inserts. It is noticed that the refinement of the grain size is more for the cylindrical inserts of $8 \mathrm{~mm}$ diameter than $6 \mathrm{~mm}$ and $10 \mathrm{~mm}$ diameter inserts. The homogeneous submicron sized grains without any structural defects are produced in the severely deformed alloy with Cu casing as shown in Fig. 7a, b. The copper casing itself acts as a source of back pressure during passing through the severe plastic deformation zone i.e. intersection of die channels.

Figure 8 shows the FE-SEM photographs of the ECAEd AA 5083 inserts with 6,8 and $10 \mathrm{~mm}$ diameters in different copper tube thicknesses after four passes in route $A$. It is noticed that the structural refinement of the AA 5083 improved in every pass and the ultrafine grain structure without any structural defects obtained after four passes of ECAE due to the provision of back pressure by the $\mathrm{Cu}$ shielding. The strain distribution is more in the core portions of the extruded bimetallic materials. The uniform distribution of strain resulted the equi-axed UFG structure in the ECAEd inserts of $6 \mathrm{~mm}$ and $8 \mathrm{~mm}$ diameter and the elongated structured is observed in the inserts of $10 \mathrm{~mm}$ diameter. After the four ECAE cycles, the average grain size of the AA 5083 inserts with $6 \mathrm{~mm}, 8 \mathrm{~mm}$ and $10 \mathrm{~mm}$ diameter are $700 \mathrm{~nm}, 500 \mathrm{~nm}$ and $400 \mathrm{~nm}$ respectively. It is observed that the rate of reduction in grain size is very less after the first pass of ECAE.

As mentioned in earlier investigation [13] the outer copper casing occupies the shear deformation zone and improves the structural homogeneity. In some investigations, the back pressure is applied on the billets during the extrusion process by an external arrangement[15]. But in this study, it is observed that the outer copper casing to the AA 5083 inserts provides smooth flow of the billets and acts as a source of back pressure during the ECAE process. The microstructural observations are having more coincidence with the above stated reports carried out with back pressure in the literature.

\subsection{Microhardness}

Vicker's microhardness measurements obtained for the ECAEd AA 5083 square billets and cylindrical inserts of $6 \mathrm{~mm}, 8 \mathrm{~mm}$ and $10 \mathrm{~mm}$ processed without and with $\mathrm{Cu}$ casing after every pass of extrusion in a direction normal to flow are presented in Table. 1. The microhardness property of the processed material increased with increasing the no. of passes for all the sizes of the inserts. The formation of ultrafine grains significantly improves the hardness value
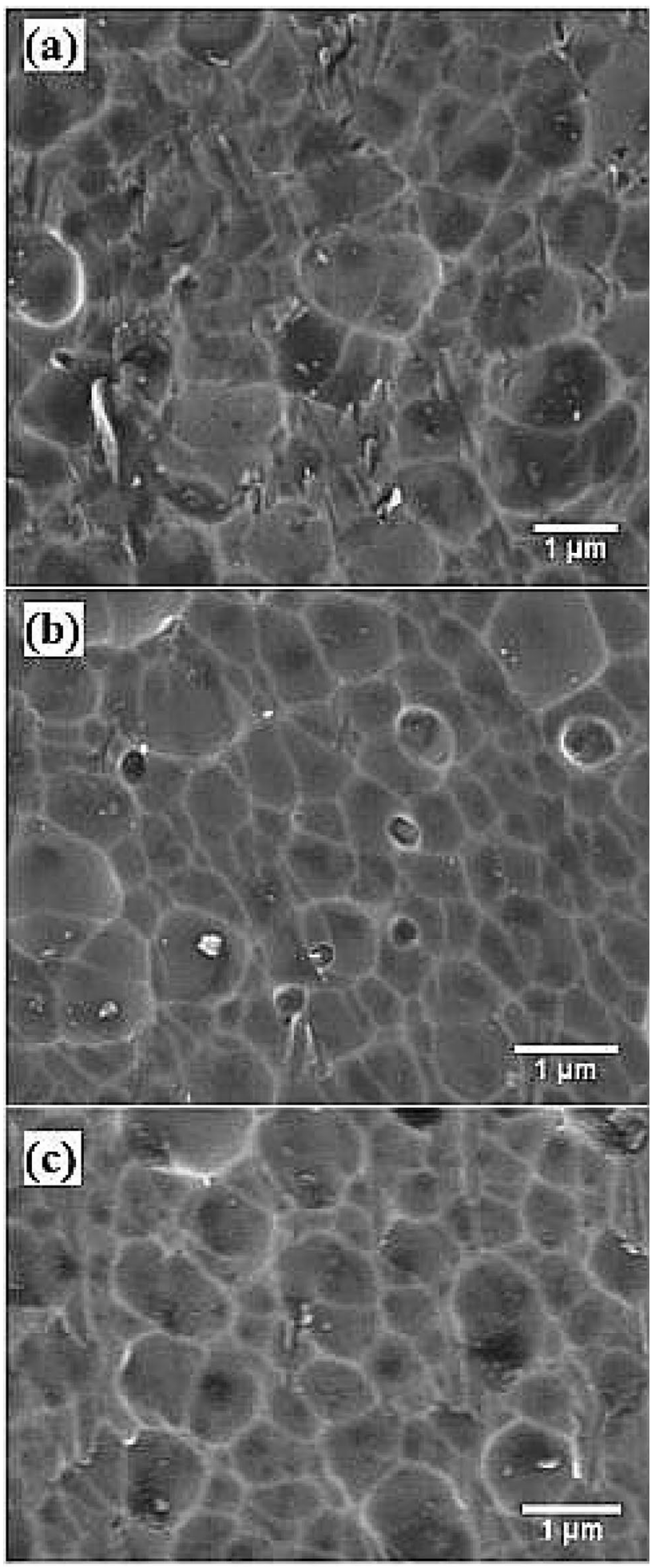

Fig. 7 SEM photographs of ECAEd AA 5083 inserts after the first pass. $\mathbf{a} \mathrm{d}=6 \mathrm{~mm}, \mathbf{b} \mathrm{d}=8 \mathrm{~mm}, \mathbf{c d}=10 \mathrm{~mm}$

of the extruded AA 5083 billets after the first pass. The microhardness values after the first pass are $97 \mathrm{VHN}, 98$ VHN, $123 \mathrm{VHN}$ and $114 \mathrm{VHN}$ for the square and cylindrical 

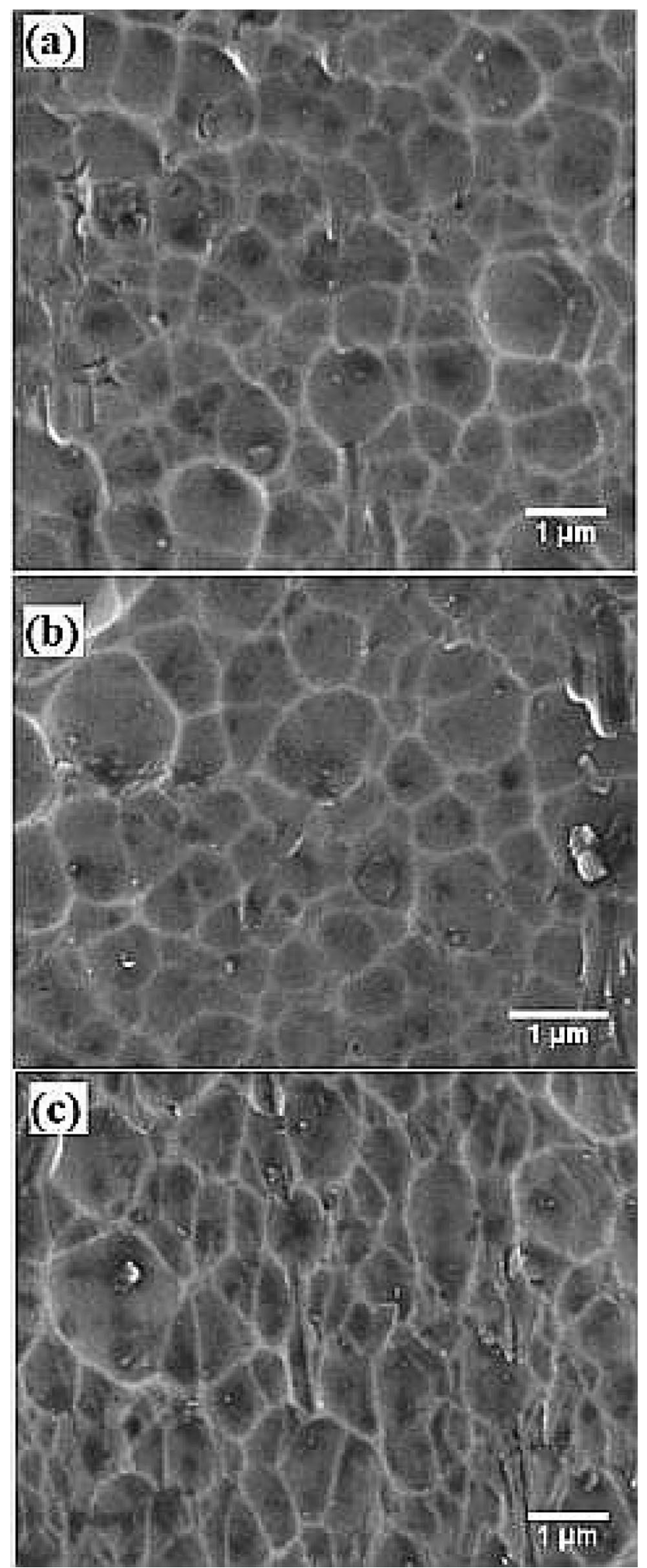

Fig. 8 SEM photographs of ECAEd AA 5083 inserts after the four passes. $\mathbf{a} \mathrm{d}=6 \mathrm{~mm}, \mathbf{b} \mathrm{d}=8 \mathrm{~mm}, \mathbf{c} \mathrm{d}=10 \mathrm{~mm}$
Table 1 Vickers microhardness measurements of AA 5083 before and after ECAE with and without Cu casing

\begin{tabular}{lcccc}
\hline Type of billet & \multicolumn{4}{l}{ Microhardness (VHN) } \\
\cline { 2 - 5 } & 1 Pass & 2 Pass & 3 Pass & 4 Pass \\
\hline Before ECAE & 69 & & & \\
Without casing & 97 & 113 & 127 & 134 \\
6 mm insert with casing & 98 & 118 & 127 & 132 \\
8 mm insert with casing & 123 & 154 & 167 & 176 \\
10 mm insert with casing & 114 & 134 & 142 & 157 \\
\hline
\end{tabular}

insert diameters of $6 \mathrm{~mm}, 8 \mathrm{~mm}$ and $10 \mathrm{~mm}$ respectively. The structural refinement in the alloy significantly increased of the value of hardness of all the processed billets even after the first pass. The value of microhardness is improved more in further extrusion cycles. The effect of the no. of ECAE cycles on microhardness measurements for different diameters of the AA 5083 inserts is shown in Fig. 9. A noticeable improvement in hardness value is observed in the extruded AA 5083 inserts after ECAE. The microhardness values are $134 \mathrm{VHN}, 132 \mathrm{VHN}, 176 \mathrm{VHN}$ and $157 \mathrm{VHN}$ for the ECAEd square billets without casing and cylindrical inserts of with $6 \mathrm{~mm}, 8 \mathrm{~mm}$ and $10 \mathrm{~mm}$ diameters covered with $\mathrm{Cu}$ casing respectively.

\subsection{Variation in microhardness of inserts covered with Cu casing at different regions}

The variations in hardness measurements of cylindrical inserts are studied thoroughly in the study. The microhardness of the extruded AA 5083 inserts with different diameters measured along the horizontal, vertical and diagonal lines on the sectioned normal plane to observe the variations in the strain distribution during the extrusion process. The variations in microhardness measurements in ECAEd AA 5083 inserts at different regions after the first pass are shown in Figs. 10, 11 and 12. The circular crosssection of the billets is changed to elliptical after ECAE. The microhardness measurements of extruded AA 5083 inserts with $6 \mathrm{~mm}$ diameter in copper bars after the first and the fourth passes are shown in Fig. 10a-d. It is observed that the value of microhardness is less on the outer regions and increases towards the core portions. The average value of the microhardness in the extruded billets at the centre is $98 \mathrm{VHN}$ and $132 \mathrm{VHN}$ after the first and the fourth passes respectively. The hardness value varies from 95 to $98 \mathrm{VHN}$ and $129 \mathrm{VHN}$ to $132 \mathrm{VHN}$ after the initial pass and the fourth pass respectively, at the outer regions due to non-uniform strain distribution at the contacting surfaces of AA 5083 inserts and copper bars. The strain induced in the $6 \mathrm{~mm}$ diameter inserts is less due to the more wall thickness of the drilled copper bars. It is observed from the 
Fig. 9 Microhardness measurements of ECAEd AA 5083 without and with Cu casing

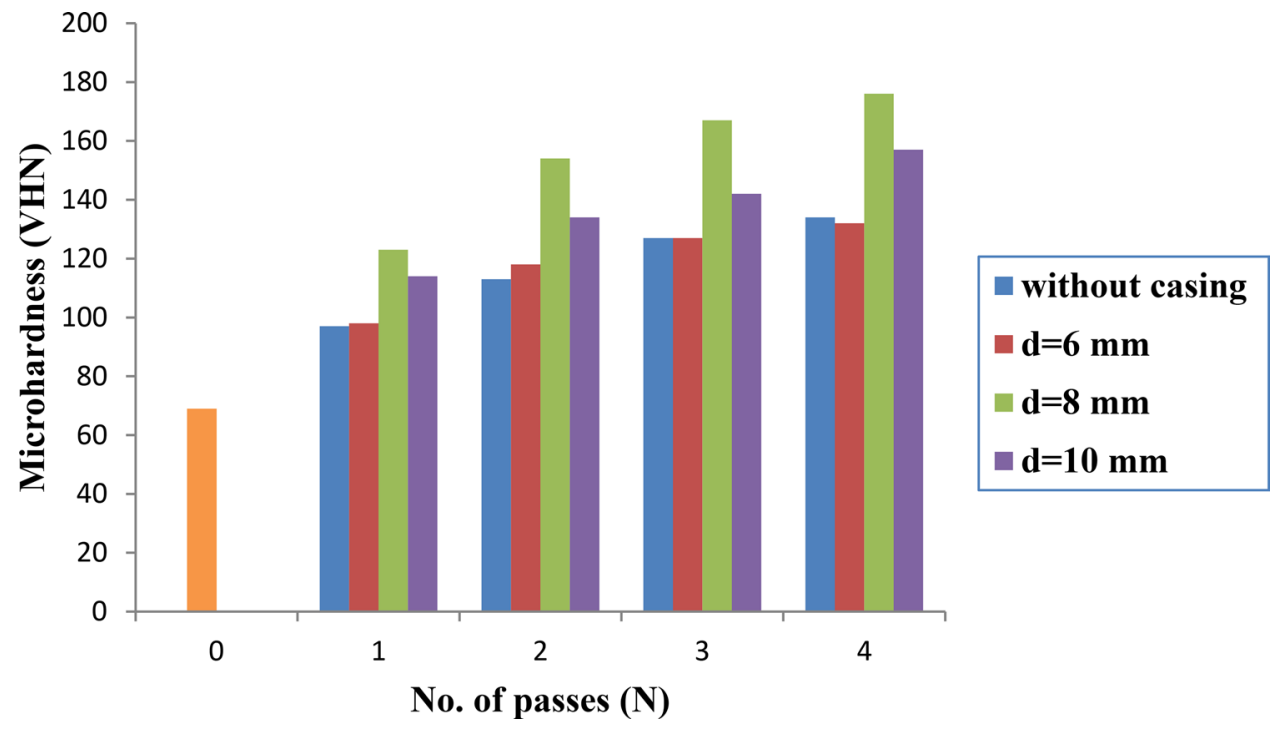

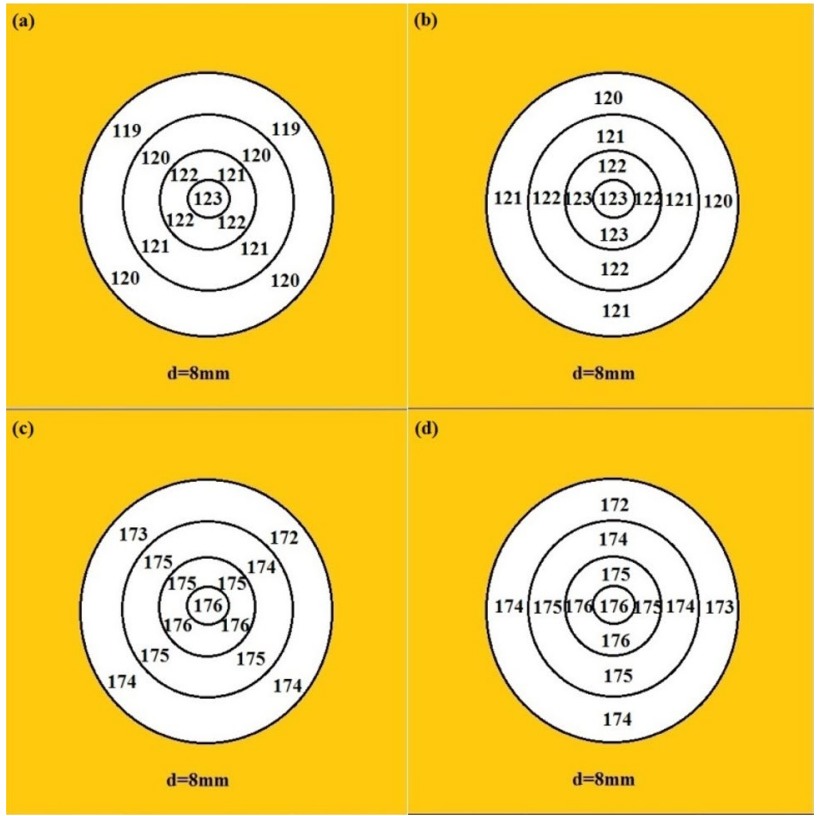

Fig. 10 Microhardness variations in ECAEd AA 5083 inserts with $6 \mathrm{~mm}$ diameter. $\mathbf{a}$, $\mathbf{b}$ After 1 st pass. $\mathbf{c}, \mathbf{d}$ after 4 th pass

Fig. 10a, c, the variation in the wall thickness of the copper bars along the diagonals has not influenced the strain distribution due to its high formability nature.

The microhardness variations in extruded AA 5083 inserts with $8 \mathrm{~mm}$ diameter in copper bars after the first and the fourth pass are shown in Fig. 11a-d. The variations in the hardness values are more in the outer regions due to less strain uniformity at the contacting surfaces of two materials. The maximum value of microhardness is obtained at the core portion and the average value is 123 VHN and 176 VHN after the first and four passes respectively. The strain induced in the bimetallic material causes

Fig. 11 Microhardness variations in ECAEd AA 5083 inserts with $8 \mathrm{~mm}$ diameter. $\mathbf{a}$, $\mathbf{b}$ After 1 st pass, $\mathbf{c}, \mathbf{d}$ After 4 th pass

the cold welding between $\mathrm{Cu}$ and AA 5083 inserts at the contacting surfaces. From the Fig. $11 \mathrm{a}$, c, it is clear that the variation in the wall thickness of the copper bars along the diagonals not influenced the strain distribution.

The microhardness measurements of AA 5083 inserts with $10 \mathrm{~mm}$ diameter in Cu bars after the ECAE are shown in Fig. 12a-d. The high amount of extrusion load acting on the bi-metallic material during extrusion process causes the cross-sectional changes in AA 5083 inserts. The variations in the hardness measurements are more in the outer regions of extruded inserts of $10 \mathrm{~mm}$ diameter as compared to $6 \mathrm{~mm}$ and $8 \mathrm{~mm}$ diameter inserts. Similar to the 


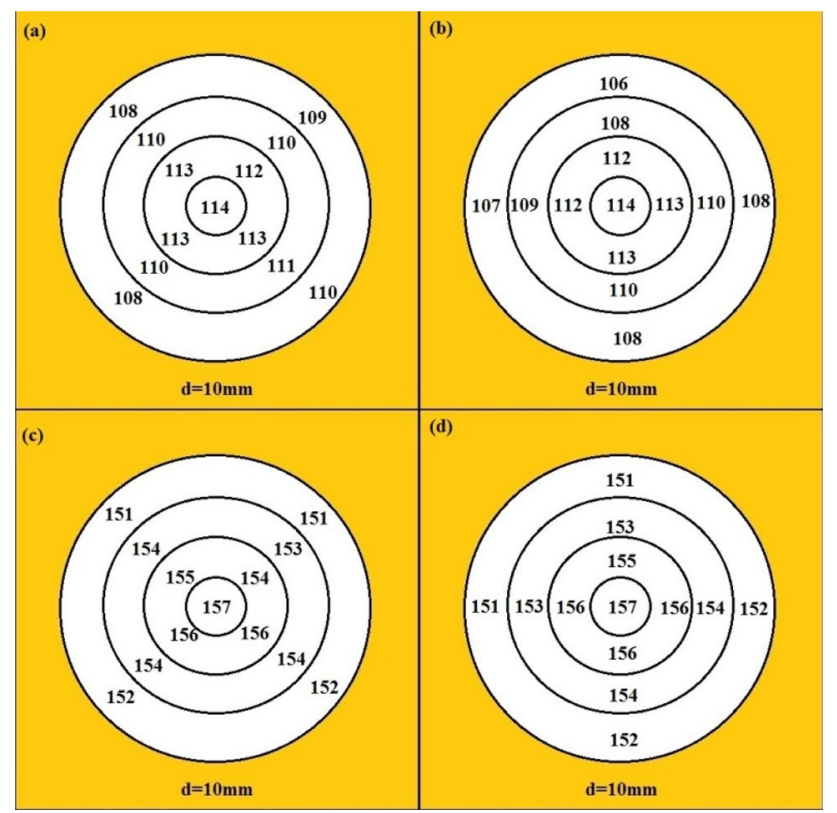

Fig. 12 Microhardness variations in ECAEd AA 5083 inserts with $10 \mathrm{~mm}$ diameter. $\mathbf{a}, \mathbf{b}$ After 1 st pass. $\mathbf{c}, \mathbf{d}$ After 4 th pass

above two cases the maximum value of microhardness is observed at the core portion and the average value are $114 \mathrm{VHN}$ and $157 \mathrm{VHN}$ after the first and the four passes. The reduction in micro hardness value of $10 \mathrm{~mm}$ diameter insert is mainly due to elongated grains along the longitudinal direction. The cold welding formed between the $\mathrm{Cu}$ and AA 5083 inserts at the contacting surfaces is high in this case as compared to the other two sizes. The variations in hardness measurents along the diagonals is more due to the high amount of load acting at the intersection of the channels during shearing of the material.

The results obtained in the present study are in good agreement with the results published by Shaeri et al. [11]. They developed the strategy to increase the homogeneity of severely deformed material by ECAE by providing the copper tube casing (CTC). They studied the effectiveness of strain distribution and distribution of micro-hardness in cylindrical billets of AA 7075 by shielded with CTC processed by ECAE using a die with channel intersection angle $(\phi)=90^{\circ}$ and outer corner angle $(\Psi)=20^{\circ}$ at room temperature. They observed the improvement of structural homogeneity and hardness in material covered with CTC. P.W.J. Mckenzie and R. Lapovok were severely deformed AA 6061 using the ECAE by providing the external back pressure through adie having channel intersection angle $(\phi)=90^{\circ}$. They observed the significant refinement in the grain size and the dislocation density by applying the back pressure in ECAE of AA 6061. The use of back pressure resulted the development of equi-axed dislocation cells with less size as compared with the absence of back pressure conditions.
The similar trend is observed in the present study also by applying the $\mathrm{Cu}$ shielding to the work material.

\section{Conclusions}

Equal channel angular extrusion of AA 5083 in square and cylindrical cross sections without and with $\mathrm{Cu}$ casing are successfully carried out in this study and the main findings and conclusions are summarized as follows.

- The initial grain size of $60 \mu \mathrm{m}$ of AA 5083 has been greatly refined and the ultrafine grains of the size in the range of $400 \mathrm{~nm}$ to $700 \mathrm{~nm}$ are observed after the four passes of ECAE.

- The use of the Cu casing reduces the amount of deformation loads and acts as a source of back pressure.

- The formation of dead metal zone is avoided by using the ductile Cu casing to the work material during the ECAE process. The uniform distribution of strain imposed on the severely deformed billets developed the homogeneous ultrafine grain structure.

- The microhardness of extruded AA 5083 significantly increased from 69 to $134 \mathrm{VHN}, 132 \mathrm{VHN}, 176 \mathrm{VHN}$ and $157 \mathrm{VHN}$ respectively for the square billets without $\mathrm{cu}$ casing and cylindrical inserts with the diameters of $6 \mathrm{~mm}, 8 \mathrm{~mm}$ and $10 \mathrm{~mm}$ covered with Cu casing after the four passes.

- The variations in copper casing thickness along the diagonals have not influenced the microhardness of the AA 5083 inserts with different diameters.

\section{Compliance with ethical standards}

Conflict of interest Author declares no conflict of interest.

\section{References}

1. El-Danaf EA, Soliman MS, Almajid AA, El-Rayes MM (2007) Enhancement of mechanical properties and grain size refinement of commercial purity aluminum 1050 processed by ECAP. Mater Sci Eng, A 458(1-2):226-234

2. Kucukomeroglu T (2010) Effect of equal-channel angular extrusion on mechanical and wear properties of eutectic Al-12Si alloy. Mater Des 31(2):782-789

3. Kawasaki M, Langdon TG (2014) Producing ultrafine-grained materials through severe plastic deformation. Emerg Mater Res 3(6):252-260

4. Djavanroodi F, Ebrahimi M (2010) Effect of die parameters and material properties in ECAP with parallel channels. Mater Sci Eng, A 527(29-30):7593-7599 
5. Iwahashi Y, Wang J, Horita Z, Nemoto M, Langdon TG (1996) Principle of equal-channel angular pressing for the processing of ultra-fine grained materials. Scripta Mater 35(2):143-146

6. Nakashima K, Horita Z, Nemoto M, Langdon TG (2000) Development of a multi-pass facility for equal-channel angular processing to high total strains. Mater Sci Eng, A 281(1-2):82-87

7. Djavanroodi F, Omranpour B, Ebrahimi M, Sedighi M (2012) Designing of ECAP parameters based on strain distribution uniformity. Prog Nat Sci Mater Int 22(5):452-460

8. Xu C, Langdon TG (2003) Influence of a round corner die on flow homogeneity in ECA pressing. Scripta Mater 48(1):1-4

9. Figueiredo RB et al (2009) Developing grain refinement and superplasticity in a magnesium alloy processed by high-pressure torsion. Mater Sci Eng, A 527(1-2):7366-7371

10. Djavanroodi F, Daneshtalab M, Ebrahimi M (2012) A novel technique to increase strain distribution homogeneity for ECAPed materials. Mater Sci Eng, A 535:115-121

11. Shaeri M, Djavanroodi F, Sedighi M, Ahmadi S, Salehi M, Seyyedein S (2013) Effect of copper tube casing on strain distribution and mechanical properties of Al-7075 alloy processed by equal channel angular pressing. J Strain Anal Eng Des 48(8):512-521
12. Naseri R, Kadkhodayan M, Shariati M (2017) An experimental investigation of casing effect on mechanical properties of billet in ECAP process. Int J Adv Manuf Technol 90(9-12):3203-3216

13. Djavanroodi F, Zolfaghari AA, Ebrahimi M, Nikbin K (2014) Route effect on equal channel angular pressing of copper tube. Acta Metall Sin (English Letters) 27(1):95-100

14. Shaeri MH, Salehi MT, Seyyedein SH, Abutalebi MR, Park JK (2014) Microstructure and mechanical properties of Al-7075 alloy processed by equal channel angular pressing combined with aging treatment. Mater Des 57:250-257

15. Bidulská J et al (2010) Influence of ECAP-back pressure on the porosity distribution. Acta Phys Pol, A 117(5):864-868

16. Varadala AB, Gurugubelli SN, Bandaru S (2018) Equal channel angular extrusion of $\mathrm{Al} 5083$ alloy with copper shielding. Emerg Mater Res 1145:29

Publisher's Note Springer Nature remains neutral with regard to jurisdictional claims in published maps and institutional affiliations. 